\title{
The role of effective human resource factors in participative management: A comparative Study between Indian and Iranian employees
}

\author{
Nader Boroumand*
}

Faculty of Management Studies, University of Delhi, Delhi 110007, India

\section{H R O N I C L E \\ A B S T R A C T}

Article history:

Received June 2, 2012

Received in revised format

28 October 2012

Accepted 30 October 2012

Available online

November 42012

Keywords:

Human resource

Participative Management

Communication

Compassion

\begin{abstract}
There is an overwhelming need to focus on the human capital and the role of this important resource on organizations' systems. In addition, there is a need for study on human resource development and participative management system. This would not be an interesting topic for study, if it were not a comparative study in the field of human capital and participative management system. Two important sectors were selected for the study i.e., Gas and Car parts companies. Gas Indian Ltd in Delhi (GAIL) and the National Gas Company of Isfahan, Iran; and also, two manufacturers of car parts in India and Iran, named Sona Group Company (in India) and Atlas Pump Sepahan (in Iran) were selected. The objectives of the study were associated with the role of some important human resource factors in participative management system. Objectives of the study are as follows: The role of communication, employees compassion, employees sentiment, reward system and training in participative management system, also if there were any significant difference on the impact of mentioned variables in Indian and Iranian organizations from the perspective of employees. The questionnaires were distributed among randomly selected employees and the researcher collected responses through the questionnaires of employees. Analysis of data was based on the SPSS (Statistical Package for the Social Sciences). Three levels of analyses were computed:

1. Descriptive analyses 2. T-Test 3. Correlation analyses.

The general observations associated with attitudes of Indian and Iranian employees about hypotheses are presented in this paper.
\end{abstract}

\section{Introduction}

In the present world, decision-making by manager only, is not sufficient because of science and technology development and lots of changes in organizations, where a single person is not able to arrange them just by himself/herself. Therefore, the manager requires to the personnel's ideas and make them responsible in order to the most and the best goal achievement of organization too. 
Successful managers attempt for participation of subordinates at workplace and one of the important elements for enable workers and employees for involvement in the organization is suitable and effective relationship among managers and employees (or workers).

\subsection{Particulars of Participative Management (Perspectives)}

There are many evidences to believe that participative management could reduce the resistant of workers against management programs. (Boroumand, 2005, p.6). According to McGregor and Douglas (1960), it is a formal method to provide an opportunity for every member of the organization to contribute his/her brain and ingenuity as well as his physical efforts for the improvement of organizational effectiveness and enhancing his/her own economic welfare. According to the International Institute of Labor studies (1968), the participation results from practices which increase the scope for employee's share of influence in decision making at various tiers of the organizational hierarchy with concomitant assumption of responsibility.

\subsection{Some Important Factors in Participative Management System}

There are literally different important factors in participative management including communication, compassion, sentiment, reward and training. Communication is exchange of meaning and transmission of messages. Communication path, in organizational hierarchy, consists of three patterns, which are horizontal path, vertical path, and oblique path. According to the first kind of communication, horizontal, there is a communication link between work groups with same levels in the organizations, which includes communication between staff and line various units in organization. In the second type of communication, the link is established vertically, which includes downwards and upward. In downwards system, communication begins from manager to employees and in upward way, Communication starts from down level to up and continues by passing reports, suggestions and requests to higher level. Another type of communication is oblique path, where communication is between personal in distinguished level and distinguished departments.

According to Gioia \& Thomas, (1996) and Thomas et al. (1993), a focus on the impacts of compassion at work incorporates some insight into how everyday interpersonal interactions serve as important cues for sense making in the workplace (Weick, 1995). Sentiment is another kind of behavior, which is closely associated with people's behaviors. Reward is another important factor, includes especial gifts, bonuses, or incentives. Rewards normally include good reviews, higher raises, greater opportunity for promotion, greater authority, etc. Herzberg et al. (Herzberg, 1959) considered that feelings of job satisfaction were more important than money for persuading people to increase productivity.

There is also more emphasis on firm's high performance and flexibility, which require an increased concentration at all levels on establishing performance goals, measures and evaluation, training when necessary, and rewarding employees based on how to achieve those goals. Finally, training is another important component. The history of training in business organizations is as long as the whole history of business organizations (Miller, 1996) because the knowledge based or skills of the normal employees in the labor market were not sufficient for the specialized responsibility within the organizations. The academic study of various forms of training, however, did not start until about a century ago (Salas \& Cannon-Bowers, 2001), when researchers started a branch of research under the name of "vocational training" (Taylor, 1916, 1947).

\subsection{The Role of Training on Teamwork}

The role of training in organization has been shown in Fig. 1. 


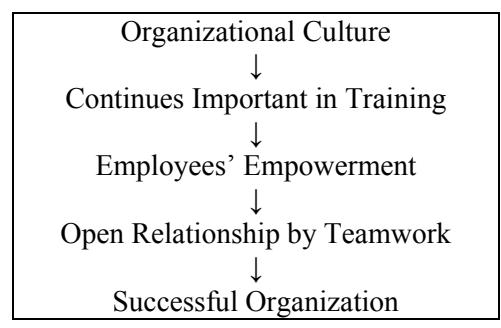

Fig. 1. Role of Training in Organization

1.4. Outcomes of participative management system in some of companies and organizations in Iran based on researches

In 1998 suggestion system was implemented in Sahand factory with 317 employees. This factory received 3158 employees' suggestion (almost 4.5 suggestions per person) and obtained about $\$ 100000$ saving cost (Boroumand, 2000). The effects of Suggestions System Performing in Governmental Organizations' from irrigation and trench channels of Guilan state firm and this research tries to compare personnel and managers' opinions about performing this management system at "Bandar Anzali customhouse", "Guilan fishery administration" and "Exploitation from irrigation and trench channels of Guilan state firm". Esmaeilzadeh and Khosravi (2008) reported the following results,

1. Performance of participative management is positively effective on organizational goals.

2. Participative management is positively effective on manager decision making.

3. Performance of participative management has positive effect on employees' innovation and creativity.

4. Counselor has effective role in quality of participative management system in organizations.

5. Manager and assessor Training have positive effect on participative management system.

6. Participative management is beneficial issue for employees.

\subsection{Participative management system in Indian organizations}

Laxmi Narayan (1984) conducted a macro level survey to study the attitudes of managers and trade union members towards selected aspects of workers' participation in management. The significant finding of the survey is that both the managers and trade union members have much faith in the potentiality and promise of workers' participation in management. Further, the study underlined the need for training to both managers and trade union members to improve their participation in decision making.

Aziz (1980) carried out another investigation on eight factories, which introduced the scheme of workers' participation in management in Karnataka. The study indicated that the respondents such as trade unions, top management personnel, workers and management representatives serving on the councils, prefer workers participation more at shop floor level when compared with board level. Further, Aziz observed in his review that the scheme of workers' participation in management was an exercise in redistribution of power and authority between workers and management for creating a committed workforce in industry.

\section{Conceptual Framework}

In this paper, we present a conceptual model to study different factors. Fig. 2 shows details of the proposed model. There are five items including suitable communication, increase of compassion, pay 
attention to sentiment, appropriate reward system, suitable planning training, which are positively associated with participative management system.

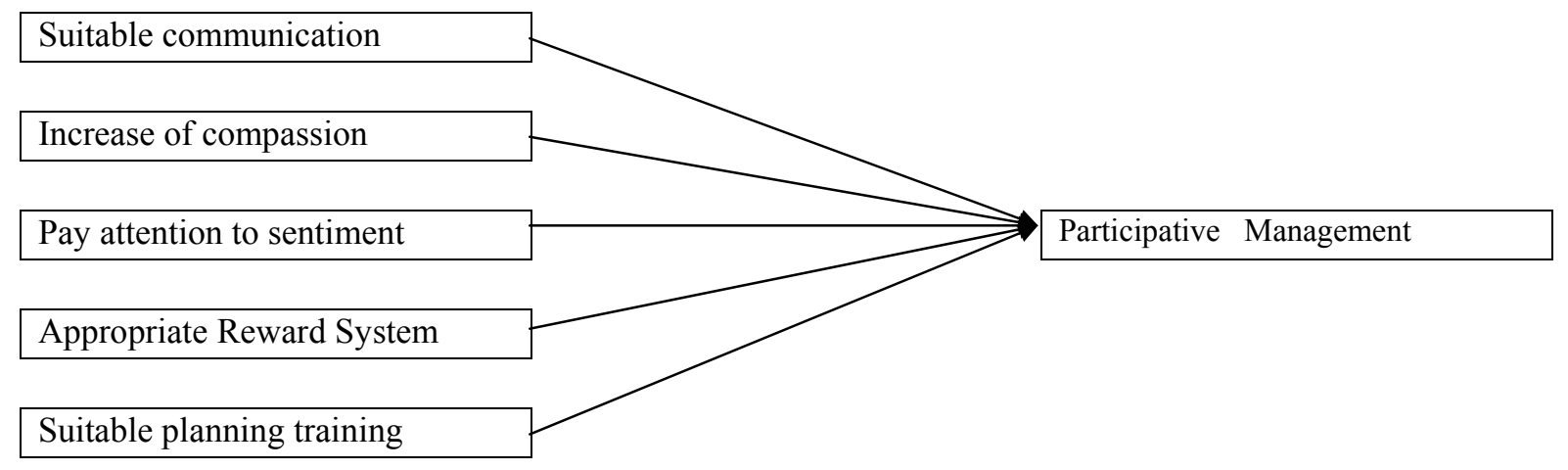

Fig. 2. Conceptual framework

In summary, the proposed study aims to establish linking variables as mentioned below:

Communication, employees' compassion and sentiment, reward system and training, are positively associated with participative management and employees involvement.

\subsection{Methodology}

The survey was performed in an attempt to understand the impact of communication, compassion, sentiment, rewards and training (elements of human capital) in the participative management system and further to do a comparison of these human capital roles in selected Iranian and Indian companies. Keeping in view this perspective, an attempt has been made in the present research to do a comparative study of the following areas and factors in organizations of the selected sectors.

1. Role of Communication in Participative Management system.

2. Role of Compassion in Participative Management system.

3. Role of Sentiment in Participative Management system.

4. Role of Rewarding in Participative Management system.

5. Role of Training in Participative Management system.

Two important sectors were selected for the study i.e., Gas and car parts companies. Although the two companies are different in various ways, but as they are extremely important in the modern industry, it is considered as comparative study. These two fields are very large, therefore, due to the paucity of time and resources, only a selection of few organizations could be considered for the study. The modern management system i.e., Participative management, is performed in Gas sector and manufacturers of car parts as well. These two companies are successful and famous in performance of participative management system in both Iran and India. The findings of the present study will give insight in developing human capital at work place through participative management.

\subsection{Objective of the Study}

The objectives of the study were as following:

1. The role of Communication in Participative Management System, also if there was any significant difference on the role of Communication in Indian and Iranian organizations from the perspective of employees. 
2. The role of Compassion in Participative Management System, also if there was any significant difference on the Compassion of employees in Indian and Iranian organizations.

3. The role of Sentiment in Participative Management System, also if there was any significant difference on the role of employees' Sentiment in Indian and Iranian organizations.

4. The role of Reward System in Participative Management System, also if there was any significant difference on the role of Reward System in Indian and Iranian organizations from perspective of employees.

5. The role of Training planning in Participative Management System, also if there was any significant difference on the role of Training Planning in Indian and Iranian organizations from perspective of employees.

\subsection{Scope of the Study}

The study was covered by the role of human resource factors in participative management system. The selected human resource factors are in the following:
a. Communication
b. Compassion
c. Sentiment
d. Rewarding
e. Training

Therefore, the questionnaires were developed regarding to above variables.

\subsection{Hypotheses}

There are five hypotheses associated with employees as follows,

Hypotheses-a: Suitable communication is positively associated with the participative management system in the organization from the perspective of employees.

Hypotheses-b: The employees are compassionated on participative management system in the organization.

Hypotheses-c: The sentiment of employees is positively associated with participative management system.

Hypotheses-d: The appropriate reward system is positively associated with participative management system in the organization from the perspective of employees.

Hypotheses-e: The suitable planning training in the organization is positively associated with participative management system from the perspective of employees.

\subsection{Selection of Respondents}

The details of the respondents' qualitative data collection are summarized in Table 1.

Table 1

Employees' respondents in selected organizations

\begin{tabular}{lll}
\hline No. & Name of organization & No. of employees respondents \\
\hline 1 & GAIL & 37 \\
2 & The National Company of Gas Isfahan-Iran & 87 \\
3 & Sona Group Company & 25 \\
4 & Atlas Pump Sepahan & 52 \\
\hline Total & & $\mathbf{2 0 1}$ \\
\hline
\end{tabular}

\subsection{Levels of analyses}

The data were collected with the help of questionnaires proposed for employees in Indian and Iranian settings. Three levels of analyses were computed:
1. Descriptive Analyses
2.T-Test
3. Correlation Analyses 
The means and standard deviations of variables from perspective of Indian and Iranian employees were computed. Correlations coefficient were computed to understand the relationship between variables from perspective of Indian and Iranian employees' samples. To compute the cross culture analyses t-test were done for all variables. The mean differences in the two group samples were tested through t-test. The t-values were computed for variables.

\section{Hypotheses Testing}

Mean Descriptive analyses, T-Test, Correlation analyses were computed for hypotheses testing associated with employees. The results will be discussed in the light of formed hypotheses. Five hypotheses and analyses associated with these hypotheses are presented below. The hypotheses are related to communication, compassion, sentiment, reward and training.

\subsection{Descriptive Analyses}

The means and standard deviations of assumption variables from perspective of Indian and Iranian samples employees are presented in Table 2.

Table 2

Mean Descriptive Assumption Variables for Indian and Iranian Sample Employees

\begin{tabular}{lcccc} 
& \multicolumn{2}{c}{ Indian Samples Employees } & \multicolumn{2}{c}{ Iranian Sample Employees } \\
& Mean & Std. Deviation & Mean & Std. Deviation \\
\hline Communication & 3.9296 & .44274 & 3.6115 & .67071 \\
Compassion & 4.2571 & .37296 & 4.0949 & .64147 \\
Sentiment & 3.7396 & .52982 & 3.2672 & .76426 \\
Reward & 3.6158 & .65045 & 3.0785 & .76172 \\
Training & 3.5699 & .59103 & 3.5612 & .82877 \\
\hline
\end{tabular}

Note; N (India=62), N (Iran=139)

Amongst variables for Indian sample employees, compassion (Mean 4.257, SD.372) had the highest mean while training (Mean 3.569, SD .591) had the lowest mean. Interestingly, amongst variables for Iranian sample employees, compassion (Mean 4.094, SD.641) had the highest mean and reward (Mean 3.078, SD .761) had the lowest mean.

\subsection{Independent Sample Test}

One of the objectives of the study was to explore if there were any significant differences in the similar assumption variables across two various countries (Iran and India). To compute this cross cultural analysis t-test was done for this factor. The mean differences in the two samples were tested through t-test. The reports of t-value for Indian and Iranian samples employees are presented in Table 3 and Table 4.

Table 3

Group Statistics of Variables for Indian and Iranian Sample Employees

\begin{tabular}{lllc}
\hline & Country & Mean & Std. Deviation \\
\hline \multirow{2}{*}{ Communication } & India & 3.9296 & .44274 \\
& Iran & 3.6115 & .67071 \\
\hline \multirow{2}{*}{ Compassion } & India & 4.2571 & .37296 \\
& Iran & 4.0949 & .64147 \\
\hline \multirow{2}{*}{ Sentiment } & India & 3.7396 & .52982 \\
& Iran & 3.2672 & .76426 \\
\hline \multirow{2}{*}{ Reward } & India & 3.6158 & .65045 \\
\hline \multirow{2}{*}{ Training } & Iran & 3.0785 & .76172 \\
& India & 3.5699 & .59103 \\
\hline
\end{tabular}

Note; N (India=62), N (Iran=139) 
Table 4

Independent Samples Test for Indian and Iranian sample Employees

\begin{tabular}{|c|c|c|c|c|}
\hline & & Levene's & quality of & $\begin{array}{c}\text { t-test for Equality of } \\
\text { Means }\end{array}$ \\
\hline & & $\mathrm{F}$ & Sig. & $\mathrm{t}$ \\
\hline & Equal variances assumed & 9.459 & .002 & 3.415 \\
\hline Communication & Equal variances not assumed & & & 3.977 \\
\hline & Equal variances assumed & 14.474 & .000 & 1.854 \\
\hline Compassion & Equal variances not assumed & & & 2.248 \\
\hline & Equal variances assumed & 8.248 & .005 & 4.414 \\
\hline Sentiment & Equal variances not assumed & & & 5.056 \\
\hline Peward & Equal variances assumed & 2.203 & .139 & 4.824 \\
\hline Reward & Equal variances not assumed & & & 5.124 \\
\hline Troining & Equal variances assumed & 9.900 & .002 & .075 \\
\hline Training & Equal variances not assumed & & & .085 \\
\hline
\end{tabular}

The t-values indicated that there were significant differences in communication, compassion, sentiment and training between Indian and Iranian employees' samples. For all of these variables Indian employees had comparatively more mean than Iranian employees. These indicated that the role of communication and training were more positive at Indian workplace as compared to Iranian workplace from perspective of employees. Indian employees were more compassionate at workplace as compared to Iranian employees and role of Indian employees' sentiment was more positive at workplace as compared to Iranian employees' sentiment. The most significant difference emerged in sentiment and the highest mean amongst the significant difference variables emerged in compassion (mean $=4.257$ ). Not significant difference was found for reward.

\subsection{Correlation Analysis}

Correlation coefficients were computed to understand the relationship between assumption variables and participative management. Table 5 shows the relationships depicted statistically between the assumption variables and participative management related to Indian and Iranian sample employees.

Table 5

Correlation of Assumption Variables for Indian and Iranian Sample Employees

\begin{tabular}{lcc} 
& \multicolumn{2}{c}{ Participative Management } \\
\cline { 2 - 3 } Communication & Indian Samples Employees & Iranian Samples Employees \\
\hline \multirow{2}{*}{ Compassion } & $.697^{* * *}$ & $.727^{* *}$ \\
& .000 & .000 \\
\hline \multirow{2}{*}{ Sentiment } & $.407^{* *}$ & $.526^{* * *}$ \\
\hline \multirow{2}{*}{ Reward } & .001 & .000 \\
\hline \multirow{2}{*}{ Training } & $.710^{* *}$ & $.680^{* * *}$ \\
& .000 & .000 \\
\hline
\end{tabular}

$\mathrm{N}$ (India=62), N (Iran=139);** Correlation is significant at the 0.01 level (2-tailed).

\subsection{The Results Related to Hypotheses}

The analyses were done for testing the hypotheses. The results are as the following sentences:

\subsection{Perspective of Indian Employees}

Mean score of communication was 3.929 ( $\mathrm{SD}=0.442)$ for Indian sample employees. The correlation between mean score of communication and participative management system was 0.697. Thus, in 
Indian setting communication was positively correlated with participative management system ( $\underline{\mathrm{r}}=$ $0.697, * * \mathrm{p}<.01$ level). Therefore, this hypothesis was supported by the data and suitable communication was positively associated with participative management system from the perspective of Indian employees.

The mean score of compassion was $4.257(\mathrm{SD}=0.372)$ for Indian sample employees. The correlation between mean score of compassion and participative management system was 0.407. Thus, in Indian setting compassion was positively correlated with participative management system $(\underline{r}=0.407, * * \underline{p}$ $<.01$ level). Therefore, this hypothesis was supported by the data and Indian employees were compassionate in participative management system in the organization.

The mean score of sentiment was $3.739(\mathrm{SD}=0.529)$ for Indian sample employees. The correlation between mean score of sentiment and participative management system was 0.710 . Thus, in Indian setting sentiment was positively correlated with participative management system $\left(\underline{r}=0.710,{ }^{* *} \underline{p}<.01\right.$ level). Therefore, this hypothesis was supported by the data and pay attention to sentiment of employees was positively related to participative management system from the perspective of Indian employees.

The mean score of reward was $3.615(\mathrm{SD}=0.650)$ for Indian sample employees. The correlation between mean score of reward and participative management system was 0.824 . Thus, in Indian setting reward was positively correlated with participative management system $(\underline{\mathrm{r}}=0.824, * * \underline{\mathrm{p}}<.01$ level). Therefore, this hypothesis was supported by the data and appropriate reward system was positively related to participative management system from the perspective of Indian employees.

The mean score of training was $3.569(\mathrm{SD}=0.591)$ for Indian sample employees. The correlation between mean score of training and participative management system was 0.757 . Thus, in Indian setting training was positively correlated with participative management system $(\underline{r}=0.757, * * \underline{p}<.01$ level). Therefore; this hypothesis was supported by the data and suitable planning training was positively related to participative management system from the perspective of Indian employees.

\subsection{Perspective of Iranian Employees}

Mean score of communication was 3.611 $(\mathrm{SD}=0.670)$ for Iranian sample employees. The correlation coefficient between mean score of communication and participative management system was 0.727. Thus, in Iranian setting communication was positively correlated with participative management system $\left(\underline{r}=0.727,{ }^{*} \underline{p}<.01\right.$ level $)$. Therefore, this hypothesis was supported by the data and suitable communication was positively related to participative management system from the perspective of Iranian employees.

The mean score of compassion was $4.094(\mathrm{SD}=0.641)$ for Iranian sample employees. The correlation coefficient between mean score of compassion and participative management system was 0.526 . Thus, in Iranian setting compassion was positively correlated with participative management system $(\underline{r}=0.526$, $*^{*} \mathrm{p}<.01$ level). Therefore, this hypothesis was supported by the data and Iranian employees were compassionate in participative management system in the organization.

The mean score of sentiment was 3.267(SD=0.764) for Iranian sample employees. The correlation coefficient between mean score of sentiment and participative management system was 0.680 . Thus, in Iranian setting sentiment was positively correlated with participative management system ( $\underline{\mathrm{r}}=$ $0.680, * * \mathrm{p}<.01$ level). Therefore, this hypothesis was supported by the data and pay attention to sentiment of employees was positively related to participative management system from the perspective of Iranian employees. 
The mean score of reward was 3.078( $\mathrm{SD}=0.761)$ for Iranian sample employees. The correlation coefficient between mean score of reward and participative management system was 0.771 . Thus, in Iranian setting reward was positively correlated with participative management system $(\underline{r}=0.771, * * \underline{p}$ $<.01$ level). Therefore, this hypothesis was supported by the data and appropriate reward system was positively related to participative management system from the perspective of Iranian employees.

The mean score of training was $3.561(\mathrm{SD}=0.828)$ for Iranian sample employees. The correlation coefficient between mean score of training and participative management system was 0.730 . Thus, in Iranian setting training was positively correlated with participative management system $(\underline{r}=0.730$, $*^{*} \mathrm{p}<.01$ level). Therefore; this hypothesis was supported by the data and suitable planning training was positively related to participative management system from the perspective of Iranian employees.

\section{Conclusion}

Suitable communication, pay attention to sentiment, appropriate reward system and suitable planning training were seen to be positively associated with participative management from perspective of Indian and Iranian employees. It was observed that Indian and Iranian employees were compassionate in participative management.

The significant differences in variables related to employees' responses are as following:

- There was a significant difference in communication, between Indian and Iranian employees. Role of communication was more positive in Indian companies as compared to Iranian companies from perspective of employees.

- There was a significant difference in compassion between Indian and Iranian employees. Indian employees were more compassionate at workplace as compared to Iranian employees.

- There was a significant difference in sentiment between Indian and Iranian employees. Role of Indian employees' sentiment was more positive at workplace as compared to sentiment of Iranian employees.

- There was no significant difference in reward between Indian and Iranian employees.

- There was a significant difference in training between Indian and Iranian employees. Role of training was more positive in Indian companies as compared to Iranian companies from perspective of employees.

Therefore, according to the results of study, compassion of Indian employees also compassion and sentiment of Iranian employees should be more considered by managers for improvement of participative management system in the selected organizations. Considering the employees' and workers' involvement at workplace in the performance appraisal system is one of the important factors to improve participative management system. Planning for more effective training and on time evaluation of training especially in the field of organizational behavior and work group, and also considering the employees and workers training in the performance appraisal system are other effective attempts toward improvement of participative management system. Moreover, planning for more effective relationship of managers with employees, workers and relationship between coworkers are some of other factors to improve participative management system.

\section{Acknowledgment}

My debts of gratitude for help and support in the completion of this research are numerous. I would like to take the opportunity to express my appreciation to the people involved in making this thesis possible. First and foremost, I would like to thank my supervisor Prof. Sunita Singh Sengupta for her invaluable support and continuous guidance. I am also deeply grateful to Prof. Raj.S Dhankar, Dean of F.M.S Delhi University, for managing the appropriate educational and research environment in F.M.S. A special tanks goes to Dr Rana Boroumand,my sister, who always stood with me to boost my 
educational career. I also want to thank all of employees who had responded to my request for filling up my questionnaires.

\section{References}

Aziz, A. (1980). Workers' Participation in Management, New Delhi, Ashish Publishing House, 86.

Boroumand, N. (2000), Design of Participative Management by Managers' and Employees' View (Thesis), Islamic Azad Najafabad univ., Iran.

Boroumand, N. (2005). Step by step toward participative management, Arkan, Iran, 64-72.

Farhanghi, A.A. (2006), Human Communication, Rasa Cultural Institute, Tehran, Iran, 6.

Herzberg, F., Mausner, B., \& Snyderman, B.B. (1959). The Motivation to Work. John Wiley \& Sons. McGregor, D. (1960), The Human Side of Enterprise, New York, McGraw Hill Book Co., p.113.

Narayan, L. (1984). Workers' Participation in Public Enterprises, Bombay, Himalaya Publishing House.

Rezaeian, A. (1991), Management Principles, The Organization of Human Science Study, Tehran (Edit Suggest), pp.227-228.

Taylor, F. W. (1916). The Principles of Scientific Management. New York, NY: Harper \& Brothers. The International Institute of Labor Studies (1968). Bulltin 5, 276.

\section{Websites}

(www.aabri.com/manuscripts/10632.pdf, as on 15.apr.2010)

(AllExperts.com, 2008)

(art-and- movement.blogspot.com/.../ compassion-true-meaning-of-good.html)

(www.citehr.com >... > Labor \& Employee Relations, as on 12.March.2010)

(www.compassionlab.com/docs/ what good is..., as on 26.Jan.2011)

(managementconsultingcourses.com, as on 10.March.2010)

(www.mit.edu,1999)

(www.solhaam.org/articles/motvtnsu.html, as on 3.Apr.2010) 